\title{
Pengaruh pelatihan asuhan gizi dalam meningkatkan kinerja ahli gizi ruang rawat inap di RSUD DR. Soetomo Surabaya
}

Indrawati Nurlela ${ }^{1}$, Tjahjono Kuntjoro ${ }^{2}$, Toto Castro $^{3}$

\section{ABSTRACT}

Background: Nutrition service department is a part of health care components in a hospital. This department is expected to have better image. Training is needed to improve work performance of dietitians in achieving a professional work. Objective: To find out the influence of nutrition training to work performance of dietitians.

Method: This study was pre-experimental with before-after design without control group. Subjects consisted of 15 dietitians and 90 inpatients at Dr. Soetomo Hospital, Surabaya. Data were collected through observation and assessment using questionnaires and check-list, and then analyzed using computer software.

Results: There were significant influences of nutrition training to dietitians' knowledge and attitude $(p<0.05)$. The competence was also significantly improved $(p<0.05)$ with the differentiation points at the first, second, and third month (50.42, 56.16, and 54.11 respectively). Nutrition service output was also significantly improved $(p<0.05)$ with the differentiation points at the first, second, and third month (12.86, 12.40 , and 11.06 respectively). There were significant differences in patient satisfaction only when they ate vegetables for lunch, vegetables for dinner, and fruits for lunch $(p<0.05)$. Conclusion: Nutrition training improved work performance of dietitians in providing service for inpatients at Dr. Soetomo Hospital, Surabaya.

KEY WORDS : nutrition service, training, performance, dietitians, inpatients

\section{PENDAHULUAN}

Pelayanan gizi merupakan salah satu komponen pelayanan kesehatan di rumah sakit. Kegiatan pelayanan gizi rumah sakit dilaksanakan oleh satu unit kerja yang disebut instalasi gizi. Dalam Surat Keputusan Menteri Kesehatan Nomor 134 Tahun 1978, instalasi gizi mempunyai 4 kegiatan, yaitu: 1) pengadaan makanan, 2) pelayanan gizi ruang rawat inap, 3) penyuluhan, konsultasi, dan rujukan gizi, serta 4) penelitian gizi terapan (1).

Kegiatan pelayanan gizi ruang rawat inap merupakan tindak lanjut dari kegiatan pengadaan makanan dari instalasi gizi. Tujuan dari kegiatan ini adalah memberikan terapi diet yang disesuaikan dengan keadaan pasien untuk mempercepat penyembuhan, mengubah sikap dan perilaku pasien terhadap makanan selama dirawat, meningkatkan peran serta masyarakat, dan mencegah kekambuhan penyakit (1).

Pada beberapa rumah sakit di Indonesia, kegiatan pelayanan gizi ruang rawat inap belum berjalan sesuai dengan yang diharapkan. Ahli gizi belum melakukan pencatatan data pasien dalam rekam medis dan evaluasi di ruang rawat belum dijalankan (2).

Keberhasilan pelayanan gizi ruang rawat inap tidak saja akan meningkatkan keberadaan instalasi gizi di rumah sakit, tetapi juga akan meningkatkan kualitas pelayanan kesehatan rumah sakit. Oleh sebab itu, seorang ahli gizi yang bertugas di ruang rawat inap dituntut dapat bekerja sebaik mungkin. Kegiatan ahli gizi ruang rawat inap tidak saja berhubungan dengan aspek terapi gizi, tetapi juga berhubungan dengan aspek pelayanan makanan dan kegiatan lain seperti mengajar dan membimbing mahasiswa atau siswa.

Mengingat banyaknya tanggung jawab dan kegiatan yang harus dilakukan, maka seorang ahli gizi ruang rawat harus dapat mengatur waktu dan mempunyai keterampilan khusus dalam melaksanakan kegiatannya. Salah satu cara yang dapat dilakukan untuk meningkatkan kemampuan dan menambah wawasan pengetahuan adalah dengan mengadakan pelatihan. Pelatihan merupakan suatu proses mengajarkan keahlian dan memberikan pengetahuan yang perlu, serta sikap agar peserta dapat melaksanakan tanggung jawabnya sesuai dengan standar (3).

Penelitian ini bertujuan untuk mengetahui pengaruh pelatihan asuhan gizi dalam meningkatkan kinerja ahli gizi ruang rawat inap. Selain itu, diharapkan juga dapat memberikan masukan pada institusi terkait mengenai perlunya pengembangan sumber daya manusia dalam rangka meningkatkan mutu pelayanan.

\section{BAHAN DAN METODE}

Penelitian ini adalah penelitian pre-eksperimental dengan rancangan before-after tanpa pembandingan (4).

\footnotetext{
1 Instalasi Gizi RSUD Dr.Soetomo Surabaya

2 Bapelkes Gombong

3 Bapelkes Salaman
} 
Penelitian dilakukan di RSUD Dr. Soetomo Surabaya dengan responden penelitian ahli gizi ruang rawat inap sejumlah 15 orang mulai bulan Agustus sampai dengan Desember tahun 2000. Responden lain adalah pasien rawat inap sejumlah 90 orang (5) dengan kriteria antara lain: telah mendapat pelayanan makanan selama tiga hari, berdiet khusus dengan bentuk makanan biasa atau lunak, dan memiliki nafsu makan yang baik.

Pengamatan dilakukan terhadap pengetahuan, sikap, kepatuhan terhadap standar, hasil pelayanan asuhan gizi, dan kepuasan pasien. Pengumpulan data menggunakan kuesioner, daftar tilik dan formulir kegiatan, serta formulir observasi sisa makanan. Penilaian terhadap pengetahuan dan sikap ahli gizi dilakukan pada saat pelatihan yaitu pretes dan postes. Untuk penilaian terhadap kepatuhan dan hasil pelayanan asuhan gizi dilakukan satu bulan sebelum pelatihan, dan penilaian setelah pelatihan dilakukan tiga kali yaitu pada bulan pertama, kedua, dan ketiga. Kepuasan pasien dilakukan sebelum pelatihan secara cross sectional. Analisis data dilakukan dengan menggunakan program komputer.

\section{HASIL}

\section{Karakteristik responden}

Ahli gizi ruang rawat yang menjadi responden dalam penelitian ini berumur antara 25-35 tahun, yang terbanyak adalah perempuan $(93,3 \%)$, mempunyai masa kerja lebih dari tiga tahun $(80 \%)$, sudah menikah $(86,7 \%)$, golongan II kepegawaian $(93,3 \%)$, dan pendidikan terakhir D3 Gizi sebanyak 93,3\% (Tabel 1).

Pasien rawat inap yang menjadi responden terbanyak dirawat di kelas III dengan diet terbanyak sebelum pelatihan adalah TKTP $(27,8 \%)$ dan setelah pelatihan adalah DM $(41,1 \%)$. Bila dilihat dari jenis kelaminnya, yang terbanyak adalah laki-laki, baik sebelum maupun setelah pelatihan, masing-masing sebesar $51,1 \%$ dan $54,4 \%$, sedangkan dari diagnosis penyakit yang terbanyak adalah penyakit dalam yaitu sebesar $50 \%$ sebelum pelatihan dan $51,1 \%$ setelah pelatihan (Tabel 2 ).

\section{Pengetahuan ahli gizi}

Pengetahuan ahli gizi diperoleh dari 30 parameter tes pengetahuan tentang pelayanan gizi ruang rawat inap. Nilai rerata sebelum pelatihan 22,4 dan setelah pelatihan 27,73 (Tabel 3). Hasil uji statistik dengan uji t didapat $p<0,05$ yang berarti terjadi peningkatan pengetahuan yang bermakna. Dari hasil ini dapat disimpulkan bahwa pelatihan asuhan gizi meningkatkan pengetahuan ahli gizi ruang rawat.

\section{Sikap ahli gizi}

Sikap ahli gizi dinilai dengan 30 parameter tes sikap terhadap pelayanan gizi rawat inap. Hasil yang didapat

TABEL 1. Karakteristik ahli gizi menurut umur, jenis kelamin, masa kerja, status perkawinan, pendidikan dan golongan kepegawaian

\begin{tabular}{lcc}
\hline \multicolumn{1}{c}{ Karakteristik } & (n) & $\%$ \\
\hline Umur & & \\
20-25 tahun & 1 & 6,7 \\
26-31 tahun & 11 & 73,3 \\
32-37 tahun & 3 & 20 \\
Jumlah & 15 & 100 \\
Jenis Kelamin & 1 & 6,7 \\
$\quad$ Laki-laki & 14 & 93,3 \\
Perempuan & 15 & 100 \\
$\quad$ Jumlah & 3 & 20 \\
Masa Kerja & 12 & 80 \\
2-3 tahun & 15 & 100 \\
>3 tahun & & \\
Jumlah & 13 & 86,7 \\
Status Perkawinan & 2 & 13,3 \\
Kawin & 15 & 100 \\
Tidak kawin & & \\
Jumlah & 14 & 93,3 \\
Pendidikan Akhir & 1 & 6,7 \\
D3 gizi & 15 & 100 \\
D4 gizi & & \\
Jumlah & 14 & 63,3 \\
Golongan Kepegawaian & 1 & 6,7 \\
$\quad$ Golongan II & 15 & \\
$\quad$ Golongan III & & \\
$\quad$ Jumlah & &
\end{tabular}


TABEL 2. Karateristik pasien menurut jenis kelamin, kelas perawatan, macam diet, diagnosis. penyakit sebelum dan setelah pelatihan

\begin{tabular}{lcccc}
\hline \multicolumn{1}{c}{ Karakteristik } & \multicolumn{2}{c}{ Sebelum } & \multicolumn{2}{c}{ Setelah } \\
\cline { 2 - 5 } & $\mathbf{n}$ & $\%$ & $\mathbf{n}$ & $\%$ \\
\hline Jenis kelamin & 46 & 51,1 & 49 & 54,4 \\
Laki-laki & 44 & 48,9 & 41 & 45,6 \\
Perempuan & 90 & 100 & 90 & 100 \\
Jumlah & & & & \\
Kelas perawatan & 2 & 2,2 & 4 & 4,4 \\
Pavilliun & 1 & 1,1 & 3 & 3,3 \\
Kelas I & 12 & 13,3 & 17 & 18,9 \\
Kelas II & 75 & 83,4 & 66 & 73,4 \\
Kelas III & 90 & 100 & 90 & 100 \\
Jumlah & & & & \\
Macam diet & 25 & 27,8 & 14 & 15,6 \\
TKTP & 23 & 25,5 & 37 & 41,1 \\
DM & 15 & 16,7 & 17 & 18,9 \\
R. garam & 7 & 7,8 & 10 & 11,1 \\
R. serat & 20 & 22,2 & 12 & 13,3 \\
Lain-lain & 90 & 100 & 90 & 100 \\
Jumlah & & & & \\
Diagnosis utama & 45 & 50 & 46 & 57,1 \\
Penyakit dalam & 16 & 17,8 & 16 & 17,8 \\
Penyakit bedah & & & & 10 \\
Non-digestive & 7 & 7,8 & 9 & 5,5 \\
Penyakit saraf & 6 & 6,6 & 5 & 15,6 \\
Pos partun & 16 & 17,8 & 14 & 100 \\
Lain-lain & 90 & 100 & 90 & \\
Jumlah & & & & \\
\hline
\end{tabular}

yaitu nilai rerata sebelum pelatihan 91,06 dan setelah pelatihan 100,06 (Tabel 3). Hasil uji statistik dengan uji t didapat $p<0,05$ yang berarti terjadi peningkatan sikap yang bermakna, sehingga dapat disimpulkan pelatihan asuhan gizi meningkatkan sikap ahli gizi terhadap pelayanan gizi ruang rawat inap.

\section{Kinerja ahli gizi}

Penilaian kinerja dilakukan terhadap kinerja proses (kepatuhan terhadap standar) dan kinerja hasil (hasil pelayanan asuhan gizi dan kepuasan pasien).

\section{Kepatuhan terhadap standar}

Penilaian kepatuhan dilakukan satu bulan sebelum pelatihan dan penilaian setelah pelatihan dilakukan tiga kali, yaitu pada bulan pertama, kedua, dan ketiga. Nilai rerata dari masing-masing hasil pengamatan menunjukkan peningkatan terutama pada postes I dan II, sedangkan pada postes III nilai rerata mulai menurun (Tabel 4, Gambar 1). Hasil uji statistik dengan uji $t$ antara pretes dengan postes I, II, dan III didapat $p<0,05$ yang menunjukkan terjadinya peningkatan kepatuhan yang bermakna.

\section{Hasil pelayanan asuhan gizi}

Data hasil pelayanan asuhan gizi didapat dari formulir kegiatan ahli gizi ruang rawat inap. Pengambilan data dilakukan satu bulan sebelum pelatihan dan setelah pelatihan dilakukan tiga kali yaitu pada bulan pertama, kedua, dan ketiga. Nilai rerata hasil pelayanan menunjukkan peningkatan, terutama pada bulan pertama setelah pelatihan, kemudian mulai menurun pada bulan kedua dan ketiga (Tabel 4, Gambar 2). Hasil uji statistik dengan uji t antara pretes dengan postes I, II, dan III didapat nilai $p<0,05$ yang menunjukkan terjadinya peningkatan hasil pelayanan asuhan gizi secara bermakna.

TABEL 3. Nilai rerata pengetahuan dan sikap sebelum dan setelah pelatihan

\begin{tabular}{lcccc}
\hline \multirow{2}{*}{ Variabel } & \multicolumn{2}{c}{ Nilai } & rerata & \multicolumn{2}{c}{ Hasil uji statistik } \\
\cline { 2 - 5 } & Sebelum & Setelah & $\mathbf{t}$ & $\mathbf{p}$ \\
\hline Pengetahuan & 22,4 & 27,73 & $-8,214$ & $0,000^{*}$ \\
Sikap & 91,06 & 100,06 & $-3,321$ & 0,003 \\
\hline
\end{tabular}

Keterangan :

* Signifikan $(p<0,05)$ 
TABEL 4. Nilai rerata kepatuhan dan hasil pelayanan sebelum dan setelah pelatihan

\begin{tabular}{lcccc}
\hline \multirow{2}{*}{ Variabel } & \multicolumn{4}{c}{ Nilai Rerata } \\
\cline { 2 - 5 } & Sebelum & $\begin{array}{c}\text { 1 bulan } \\
\text { setelah }\end{array}$ & $\begin{array}{c}\text { 2 bulan } \\
\text { setelah }\end{array}$ & $\begin{array}{c}\text { 3 bulan } \\
\text { setelah }\end{array}$ \\
\hline Kepatuhan & 31,42 & 81,84 & 87,58 & 85,53 \\
Hasil pelayanan & 3 & 15,86 & 15,4 & 14,06 \\
\hline
\end{tabular}

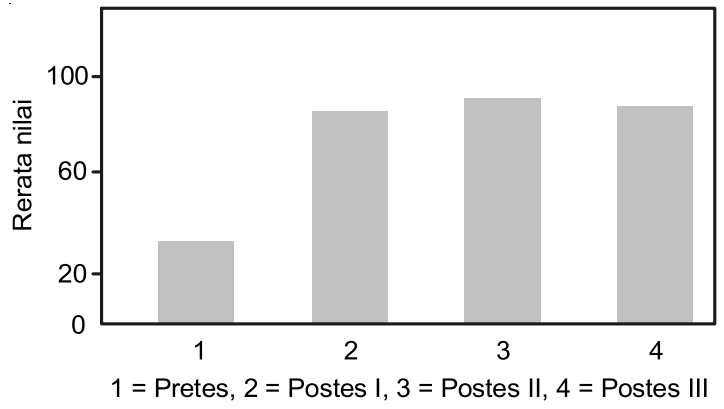

GAMBAR 1. Rerata nilai kepatuhan

\section{Kepuasan Pasien}

Penilaian terhadap kepuasan pasien dilakukan dengan cara melakukan pengamatan terhadap sisa makanan pada tiap macam makanan, meliputi makanan pokok, lauk hewani, lauk nabati, sayur, dan buah pada waktu makan pagi, siang, dan malam. Kriteria kepuasan meliputi puas bila sisa $\leq 1 / 4$ porsi dan tidak puas bila sisa $>1 / 4$ porsi.

Dari hasil pengamatan yang diuji statistik dengan chi-square diketahui bahwa tidak ada perbedaan yang bermakna kepuasan pasien sebelum dan setelah pelatihan asuhan gizi pada makanan pokok, lauk hewani, dan lauk nabati pada waktu makan pagi, siang, dan malam, kecuali pada sayur siang $(p=0,039)$, sayur malam $(p=0,04)$, dan buah siang $(p=0,018)$.

Hasil pengamatan kriteria puas sebelum dan setelah pelatihan asuhan gizi pada sayur siang sebesar $74,4 \%$ dan $60,0 \%$ (Tabel 5); sayur malam sebesar $63,3 \%$ dan $82,2 \%$ (Tabel 6); buah siang sebesar $68,4 \%$ dan $87,8 \%$ (Tabel 7).

Untuk mengendalikan variabel luar yaitu: jenis kelamin, kelas perawatan, macam diet, dan diagnosis penyakit terhadap kepuasan pasien dilakukan analisis regresi logistik. Berdasarkan hasil uji regresi logistik

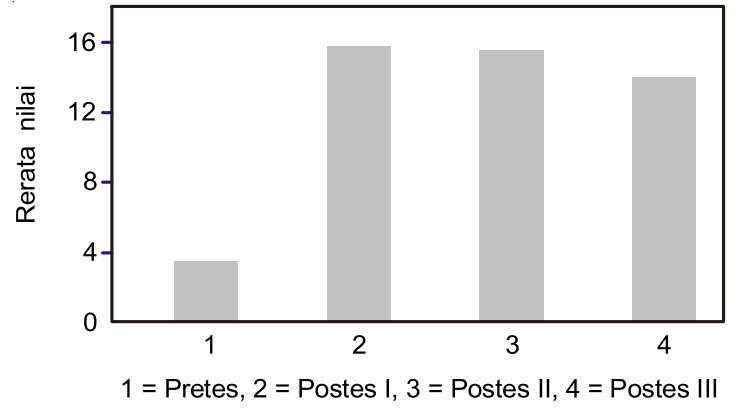

GAMBAR 2. Nilai rerata hasil pelayanan gizi

tersebut, ternyata tidak ada variabel yang bermakna pengaruhnya pada kepuasan pasien pada tiap macam makanan. Menurut Dube et al. (6), kepuasan pasien dipengaruhi oleh kualitas makanan, ketepatan waktu penyajian, reliabilitas pelayanan, temperatur makanan, sikap petugas yang melayani pasien pada waktu makan, sikap petugas distribusi makanan, dan perilaku lain terhadap pasien.

\section{BAHASAN}

Pengetahuan ahli gizi meningkat setelah pelatihan asuhan gizi, demikian pula dengan sikap ahli gizi (Tabel 3). Hal ini sesuai dengan tujuan pelatihan yaitu meningkatkan pengetahuan dan sikap peserta pelatihan. Pengetahuan merupakan domain yang sangat penting untuk menimbulkan tindakan seseorang, terutama pada orang dewasa. Terbentuknya perilaku baru dimulai dari penguasaan pengetahuan, yang selanjutnya menimbulkan kesadaran, dan akhirnya berperilaku sesuai dengan pengetahuan yang dimiliki. Sikap yang meningkat terhadap pelayanan gizi ruang rawat inap disebabkan peserta dalam hal ini ahli gizi telah mendapat pelatihan dengan materi yang sesuai.

TABEL 5. Distribusi frekuensi kepuasan pasien terhadap sayur siang sebelum dan setelah pelatihan

\begin{tabular}{lcccc}
\hline \multirow{2}{*}{ Kriteria kepuasan } & \multicolumn{2}{c}{ Sebelum } & \multicolumn{2}{c}{ Setelah } \\
\cline { 2 - 5 } & $\mathbf{n}$ & $\mathbf{\%}$ & $\mathbf{n}$ & \% \\
\hline Puas & 67 & 74,4 & 54 & 60,0 \\
Tidak puas & 23 & 25,6 & 36 & 40,0 \\
Jumlah & 90 & 100 & 90 & 100 \\
\hline
\end{tabular}


TABEL 6. Distribusi frekuensi kepuasan pasien terhadap sayur malam sebelum dan setelah pelatihan

\begin{tabular}{lcccc}
\hline \multirow{2}{*}{ Kriteria kepuasan } & \multicolumn{2}{c}{ Sebelum } & \multicolumn{2}{c}{ Setelah } \\
\cline { 2 - 5 } & $\mathbf{n}$ & $\mathbf{\%}$ & $\mathbf{n}$ & $\mathbf{\%}$ \\
\hline Puas & 57 & 63,3 & 74 & 82,2 \\
Tidak puas & 33 & 36,7 & 16 & 17,8 \\
Jumlah & 90 & 100 & 90 & 100 \\
\hline
\end{tabular}

TABEL 7. Distribusi frekuensi kepuasan pasien terhadap buah siang sebelum dan setelah pelatihan

\begin{tabular}{lcccc}
\hline \multirow{2}{*}{ Kriteria kepuasan } & \multicolumn{2}{c}{ Sebelum } & \multicolumn{2}{c}{ Setelah } \\
\cline { 2 - 5 } & $\mathbf{n}$ & $\mathbf{\%}$ & $\mathbf{n}$ & $\mathbf{\%}$ \\
\hline Puas & 39 & 68,4 & 43 & 87,8 \\
Tidak puas & 18 & 31,6 & 6 & 12,2 \\
Jumlah & 57 & 100 & 49 & 100 \\
\hline
\end{tabular}

Setelah pelatihan asuhan gizi, terjadi peningkatan kepatuhan ahli gizi terhadap standar. Hal ini disebabkan ahli gizi telah mempunyai pengetahuan dan sikap yang positif terhadap pelayanan gizi ruang rawat inap dan didukung tersedianya sarana untuk melakukan kegiatan tersebut. Penurunan kepatuhan yang terjadi pada bulan ketiga setelah pelatihan kemungkinan karena tidak adanya pertemuan rutin yang biasa diadakan setiap bulan untuk pembinaan.

Dengan memiliki pengetahuan yang lebih baik mengenai asuhan gizi, ahli gizi akan bersikap dan bertingkah laku positif terhadap pelayanan gizi ruang rawat inap. Hal ini diwujudkan dengan makin rajinnya ahli gizi melakukan asuhan gizi kepada pasien, sehingga akan meningkatkan hasil pelayanan asuhan gizi. Kemungkinan lain yang mempengaruhi hasil pelayanan gizi adalah adanya dukungan dari organisasi berupa penyediaan sarana dan motivasi dari pimpinan. Penilaian terhadap hasil pelayanan dilakukan pada bulan pertama, kedua, dan ketiga setelah pelatihan. Jangka waktu tersebut terlalu singkat bila dibandingkan dengan Departemen Kesehatan R.I. (7) yang paling tidak memerlukan waktu enam bulan untuk penilaian hasil kegiatan. Namun demikian, dalam waktu yang cukup singkat ini, kenaikan hasil kegiatan sudah dapat terlihat pada bulan pertama setelah pelatihan. Hal ini disebabkan ahli gizi tidak melakukan pencatatan kegiatan yang dilakukan sebelum pelatihan.

Hasil pengamatan terhadap kepuasan pasien menunjukkan tidak ada perbedaan bermakna kepuasan pasien sebelum dengan setelah pelatihan asuhan gizi pada sebagian besar makanan, yaitu pada makanan pokok, lauk hewani, dan lauk nabati untuk waktu makan pagi, siang, dan malam. Hal ini kemungkinan disebabkan pengamatan terhadap sisa makanan hanya dilakukan satu hari. Ada kemungkinan pasien menyukai makanan yang disajikan pada saat sebelum pelatihan sehingga konsumsinya baik. Di samping itu, ada faktor-faktor lain yang mempengaruhi konsumsi pasien seperti terapi diet DM yang banyak dilakukan setelah pelatihan, sehingga konsumsi sayur dan buah lebih banyak.

\section{KESIMPULAN DAN SARAN}

Dari hasil penelitian ini dapat disimpulkan bahwa pelatihan asuhan gizi yang diberikan kepada ahli gizi ruang rawat inap RSUD Dr. Soetomo Surabaya meningkatkan pengetahuan ahli gizi tentang pelayanan gizi ruang rawat inap dan meningkatkan sikap ahli gizi terhadap pelayanan gizi ruang rawat inap. Di samping itu, pelatihan asuhan gizi juga meningkatkan kinerja ahli gizi, yaitu kepatuhan terhadap standar dan hasil pelayanan.

Untuk mempertahankan kinerja yang telah meningkat perlu dilakukan supervisi secara periodik dari pimpinan dan hasilnya diumpanbalikkan kepada yang bersangkutan. Kepuasan pasien yang merupakan salah satu indikator kinerja hasil tidak berbeda, kecuali pada sayur siang, sayur malam, dan buah siang. Untuk itu perlu dilakukan penilaian kepuasan pasien dengan pengamatan terhadap sisa makanan selama tiga hari berturut-turut, agar hasil yang didapat lebih akurat.

\section{RUJUKAN}

1. Departemen Kesehatan RI. Buku Pedoman Tehnis Pelayanan Gizi Rawat Nginap dan Rawat Jalan di Rumah Sakit. Jakarta: Depkes RI; 1991.

2. Almatsier S. Profil Pelayanan Gizi Rumah Sakit di 10 RS. Panduan Makalah pada Kongres PERSAGI; Bandung; 1995. 
3. Cushway B. Human Resources Management PT Elex Media Komputindo. Jakarta: Gramedia; 1999.

4. Kumar R. Research Methodology, A Step-by-Step Guide for Beginners. London: Sage Publications Ltd; 1999.

5. Lemeshow S, Hosmer D, Klar J. 1990. Adequacy of Sample Size in Health Studies. (Terjemahan) Pramono D. Yogyakarta: UGM Press; 1997. h. 49-52.
6. Dube L, Trudeau E, Belanger MC. Determining The Complexity of Patient Satisfaction with Foodservice. J Am Diet Assoc 1994;4:394-8.

7. Departemen Kesehatan RI. Pedoman Pengukuran Keberhasilan Pelatihan. Jakarta: Depkes RI; 1995. 